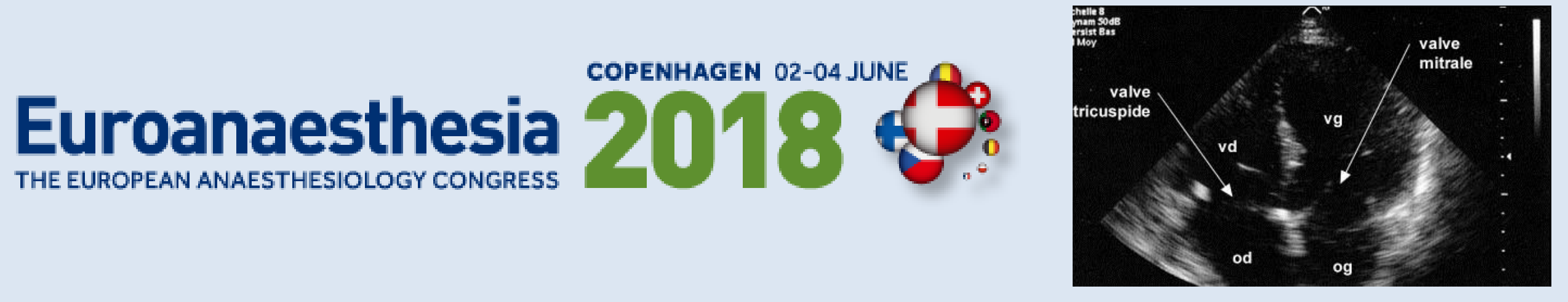

\title{
Is systematic echocardiography useful in elderly parturients ?
}

Monitoring,echocardiography, Age factors, Monitoring,cardiopulmonary

\author{
C. Ruault ${ }^{1}$, K. Bouattour ${ }^{1}$, M. Soued ${ }^{1}$, F. J. Mercier ${ }^{1}$, A. Le Gouez ${ }^{1}$ \\ ${ }^{1}$ Department of anesthesiology, Antoine Béclère Hospital - APHP \& School of Medicine, South \\ University of Paris - Clamart (France)
}

\section{BACKGROUND AND GOAL OF STUDY :}

Maternal mortality in obstetric setting rises significantly in elderly patients and is namely 6 times higher between 40 to 44 years old (y.o.) than between 25 to 29 y.o. This increase is mainly related to cardiovascular diseases, which represent the leading cause of maternal death in highincome countries [1]. Consequently, in our hospital, trans-thoracic echocardiography (TTE) is systematically performed in elderly parturients (older than 40 years) during pregnancy. However, the benefit of such a practice is not demonstrated and no recommendations in the literature support it.

\footnotetext{
2. PATIENTS AND METHODS : pregnancy. pathological were

- $\quad$ LVEF $<55 \%$,

- diastolic dysfunction (E/A $\geq 1$ ),

- valvulopathy,

- $\quad$ SPAP > $35 \mathrm{mmHg}$,

- $\quad$ hypo- or a-kinetic areas

- pericardial effusion,

- $\quad$ cardiac cavity size anomaly.
}

Between July and December 2015, we carried out a retrospective study on 20 consecutive parturients, older than 40 years that had a systematic TTE during

Ultrasound characteristics considered to be

\section{3a. RESULTS :}

Among these 20 parturients, 75\% were primiparous, 10\% had a twin pregnancy, 42\% had a medically assisted reproduction, $20 \%$ had a body mass index (BMI) > 30 $\mathrm{kg} / \mathrm{m} 2$ and $10 \%$ had a chronic hypertension prior to pregnancy.

Seventy percent $(n=14)$ of the TTE were normal. The 6 remaining TTE showed : minimal tricuspid insufficiency $(n=2)$ associated for 1 patient with an aspect of interauricular septal aneurysm without significant shunt, minimal diastolic dysfunction $(n=1)$, minimal mitral insufficiency associated with interauricular septal aneurysm without significant shunt $(n=2)$ and small mitral valve prolapse $(n=1)$. No peri-partum complications occurred in these 20 parturients.

3b. RESULTS :

\begin{tabular}{|c|c|c|}
\hline & Normal TTE & Remaining TTE \\
\hline $\begin{array}{c}\text { Multiparous } \\
\text { Medically assisted } \\
\text { reproduction }\end{array}$ & 4 & 1 \\
\hline BMI $\geq 30 \mathrm{~kg} / \mathrm{m}^{2}$ & 3 & 3 \\
\hline Chronic hypertension & 2 & 1 \\
\hline Twin pregnancy & 0 & 0 \\
\hline
\end{tabular}

Distribution of normal and remaining TTE according to the specific characteristics of parturients
4. CONCLUSION :
Systematic TTE in elderly parturients, in absence of known heart disease, did not reveal any significant abnormality that modified their peri-partum management. Therefore, this small series does not support planning systematic TTE during pregnancy on the sole basis of advanced age. 